\title{
Parameter inversion and location determination of evolutionary weak layer for open-pit mine slope
}

\author{
Zhao Hongze $^{1,2} \cdot$ Wang Dongyu ${ }^{1} \cdot$ Ma Ming $^{3} \cdot$ Zheng Kaihui $^{4}$
}

Received: 23 May 2019/Revised: 5 May 2020/Accepted: 2 June 2020/Published online: 13 June 2020

(C) The Author(s) 2020

\begin{abstract}
In light of the complex and dynamic mechanical properties of evolving weak strata in open-pit mines, and the consequent difficulty of determining their mechanical parameters, this study uses the ultimate balance theory, along with the back analysis method combined with monitoring data on field displacement, to carry out parameter inversion using the FLAC3D numerical simulation software. The edge slope of a working pit of the Weijiamao open-pit mine was used as research object to this end. As the results obtained by the constitutive model were consistent with the field monitoring data, the evolving weak strata in the slope and the position of the landslide in the mine could be obtained. The landslide was directed northeast. The mechanism of the edge slope of the working pit was identified as unloading shear failure, and the feasibility of the method of parameter inversion was verified. The internal friction angle $\phi$ and cohesion $C$ of evolving weak strata in the slope of the open-pit mine were also obtained, where this compensated for the deficiency of laboratory tests and enabled the transformation from qualitative to quantitative analysis. This can provide a reliable basis for the safe operation of open-pit mines.
\end{abstract}

Keywords Open-pit mine $\cdot$ Evolution of weak layer $\cdot$ Inverse analysis $\cdot$ Monitoring data $\cdot$ Numerical simulation

\section{Introduction}

As the depth of open-pit mines increases with developments in mining technology, the stability of the slope of the mine becomes particularly important. The geotechnical mechanical parameters of the slope are important for analyzing its stability (Kesavan and Bekir 2020). Whether

Zhao Hongze

hzzhao78@163.com

1 School of Energy and Mining Engineering, China University of Mining and Technology, Beijing 100083, China

2 State Key Laboratory for Geomechanics and Deep Underground Engineering, China University of Mining and Technology, Beijing 100083, China

3 Beijing Reliance Coal Research Institute, Beijing 100083, China

4 North Weijiamao Coal Power Co. Ltd., Ordos 010308, Inner Mongolia, China accurate mechanical parameters of the slope can be obtained directly affects the safe and smooth operation of open-pit mining projects (Chang and Liu 2018; Zhao et al. 2020). Open-pit mines where the stability of the slope is controlled by the weak layer are susceptible to slides along it, which poses a significant threat to its safe operation ( $\mathrm{Lu}$ and Zhu 2014; Cao et al. 2015). The inclinometer can be used to obtain real-time data on the slope in the context of research on the back analysis method ( $\mathrm{Li}$ et al.1998; Liu et al. 2004). Based on such data, equivalent parameters required by the engineering design can be obtained by using the mathematical and physical back analysis model (Liu et al. 2006). Cao et al. (2015) analyzed the stability of the slope by verifying a numerical simulation through field monitoring data from an inclinometer. Parameter inversion analysis can help economically obtain reasonable parameter values. The common methods used for this purpose include normal and back analysis, and inverse analysis (Zhang et al. 2005; Hu et al. 2005; Tian and Zhou 2005; Shang et al. 2019). Bai (2018) used limit equilibrium 
theory to conduct an inversion analysis of the parameters of the strength of deformed rock mass by using a safety factor, and accurately determined its strength-related parameters. This can provide a parametric basis for an analysis of the stability of deformed rock mass and even the slope. Lu and Han (2018) obtained the physical and mechanical indices of the sliding surface through back analysis, and obtained the mechanical indices of the rock and Earth masses in other locations using experiments. Compared with the genetic algorithm (Holland 1992) and the artificial neural network (Feng et al. 1997), the back analysis method can more correctly reflect and predict the mechanical behaviors of geotechnical structures.

While studies in the area have examined slopes with weak layers in open-pit mines by means of field investigation, theoretical analysis, numerical simulation, back analysis, and other methods to obtain accurate mechanical parameters, the relevant research and analyses have assumed a weak layer with relatively stable properties, and few have considered an evolving weak layer with unstable properties. The instability of the evolution of the weak layer causes the slope to remain in an unstable state of critical sliding after a landslide. Features of the evolving weak layer make it difficult to extract the ideal sample from it through drilling and sampling, because of which it is difficult to obtain more accurate mechanical parameters of the layer in laboratory tests. This makes it impossible to quantitatively analyze the stability of the slope of open-pit mines. Therefore, it is important to study the parameter inversion and means of determining the location of the evolving weak layer of the slope of open-pit mines.

\section{Geological overview of research area}

We used the Weijiamao open-pit mine as research object for this study. The mining area is located in the Ordos Loess Plateau, China. Owing to the depth of the groundwater there, which is far beyond its limit of depth of evaporation, the area is rich in typical perched groundwater. Thin mudstone is present in the slope as a water-resisting layer, where its contact surface has been soaked by groundwater for a long period to form a typical "evolving weak layer" of the open-pit mine. Porosity is relatively low, water content and saturation are high, and its strengthrelated features mainly manifest as rheological features. With a constant change in the stress state over time, the shear strength decreases to threaten the stability of the slope. As the working slope of the Weijiamao open-pit mine was stripped, the excavation of the foot of the slope led to a release of stress, and rock and Earth mass slid along the free direction to form tension cracks inside the soil. With the expansion of the surface of these tension cracks, stress was released, and the surface developed to form a through-slide surface with the structural surface of the evolving weak layer at the bottom of the slope, and thus caused the working slope to slide as a whole. However, owing to the weak layer, it remained in an unstable state of critical sliding. It was important to the stability of the working slope to invert the parameters of its evolving weak layer to locate it.

Figure 1 shows the area of the landslide of the working slope of the Weijiamao open-pit mine. A typical section (see Fig. 2) was selected from the core-406 $\mathrm{m}$ long and 96 $\mathrm{m}$ high. According to an analysis of the drilling lithology, the lithology of the section was as follows from top to bottom: silty sand, silt, silty clay, strongly weathered mudstone, and strongly weathered sandstone.

\section{Determining position of sliding zone}

\subsection{Monitoring surface displacement}

Three monitoring lines (P-1, P-2, P-3) were set on the sliding surface and nine monitoring points (DW1-9) were arranged to monitor surface displacement. The layout of the Global Positioning System monitoring points is shown in Fig. 3.

As shown in Table 1, the azimuth angles of DW1, DW2, DW3, DW6, DW7, DW8, and DW9 were relatively close to one another, ranging from $31^{\circ}$ to $48^{\circ}$. Therefore, the direction of sliding of the body of the slope could be roughly determined.

As shown in Fig. 4, the displacement of monitoring points DW1, DW2, DW8, and DW9 on monitoring line P-2 was large. According to an analysis of the displacement data at monitoring points on the flat plate, points at +1128 $\mathrm{m}$ and $+1144 \mathrm{~m}$ on the flat plate (DW6, DW7, DW8, and DW9) had larger horizontal displacements than those of monitoring points DW1, DW2, and DW3 at $+1260 \mathrm{~m}$ on the flat plate. The vertical displacement of monitoring points DW1, DW2, and DW3 at $+1260 \mathrm{~m}$ on the flat plate was larger, which indicates that the displacements of rock and soil on the flat plate were mainly located at $+1260 \mathrm{~m}$ and beyond, whereas the rock and soil at $+1128 \mathrm{~m}$ and $+1144 \mathrm{~m}$ on the flat plate mainly slid toward the free surface.

The cumulative displacement obtained through GPS monitoring is shown in Fig. 5. The P-2 monitoring line, where DW1 (No. 1), DW2 (No. 2), DW8 (No. 8), and DW9 (No. 9) were located, was approximate to the central axis of the slope of the landslide, and the monitoring points DW3 (No. 3), DW5 (No. 5), and DW6 (No. 6) converged to the central axis. Common features of the displacement vector at each point in the body of the slide in the critical sliding 


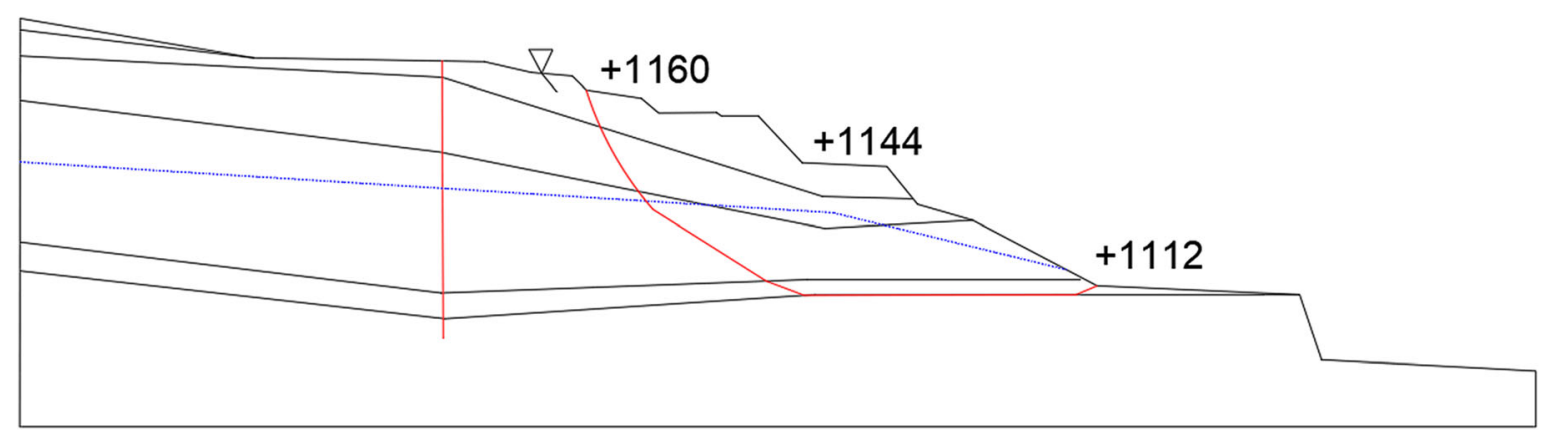

Fig. 1 Simplified model of profiles of typical strata in Weijiamao open-pit mine

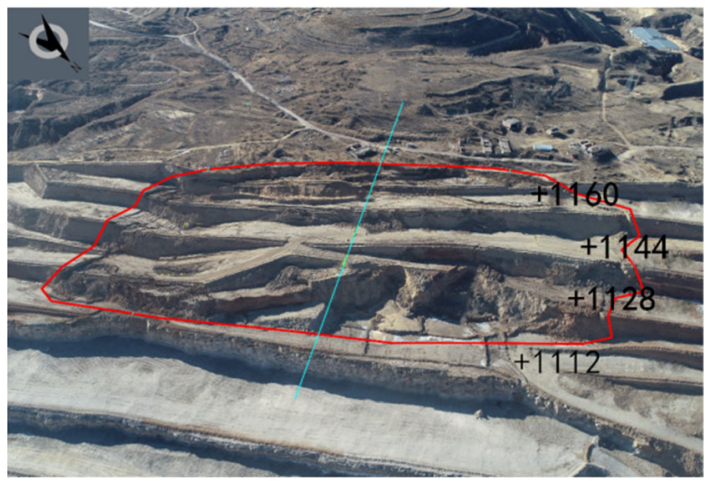

Fig. 2 Section location diagram

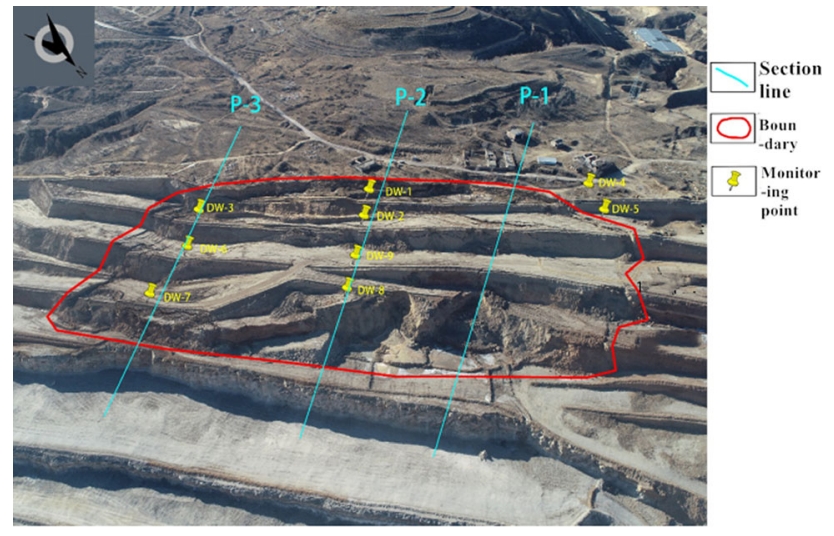

Fig. 3 Layout of monitoring station

state are shown in Fig. 6. If the displacement vector was disordered in the plane, the slope was not in a state of critical sliding. According to the trajectory of the vector shown in Fig. 5, the displacement vector exhibited a certain regularity, indicating that the slope was in the state of critical sliding, mainly in the northeast direction.
Table 1 Cumulative displacement values of GPS monitoring points in landslide area

\begin{tabular}{lllc}
\hline $\begin{array}{l}\text { Point } \\
\text { No. }\end{array}$ & $\begin{array}{l}\text { Cumulative horizontal } \\
\text { displacement }(\mathrm{mm})\end{array}$ & $\begin{array}{l}\text { Azimuth } \\
\left(^{\circ}\right)\end{array}$ & $\begin{array}{l}\text { Cumulative vertical } \\
\text { displacement }(\mathrm{mm})\end{array}$ \\
\hline DW1 & 1398.08 & 41.9 & -2510.4 \\
DW2 & 1176.65 & 48 & -1454.6 \\
DW8 & 3228.2 & 36.2 & -305.1 \\
DW9 & 2933.49 & 38.9 & -166.4 \\
DW3 & 2179.61 & 31 & -1551.1 \\
DW6 & 2050.65 & 37.9 & -1285.3 \\
DW7 & 2530.78 & 46.5 & -128.8 \\
DW4 & 57.89 & 32.2 & -50.5 \\
DW5 & 102.14 & 48.2 & -44.6 \\
\hline
\end{tabular}

\subsection{Deep displacement monitoring}

The monitored deformation-related data of deep rock mass can be used to determine the stability of the slope and the potential sliding surface. The curve of the cumulative depth of displacement reflects the process of changes in stress and features of the deformation of the rock mass in different ranges of depth. According to the curve of underground displacement monitoring, types and features of the deformation and destruction of the slope can be determined, as can the position of the sliding surface or the slide zone.

We selected sections P-1, P-2, and P-3, and drilled holes at ZK1, ZK2, ZK3, ZK4, ZK5, and ZK6. We installed inclinometer tubes at each drilling location to accurately measure horizontal displacement inside the sliding body using a sliding inclinometer, and thus determined the position of the layer of the slide zone. Owing to the large rate of deformation of the sliding body, a $5 \mathrm{~mm} \times 5 \mathrm{~mm}$ galvanized, national standard square steel pipe was used to extend the monitoring time as much as possible. The distribution of the drilling is shown in Fig. 7. 
(a)

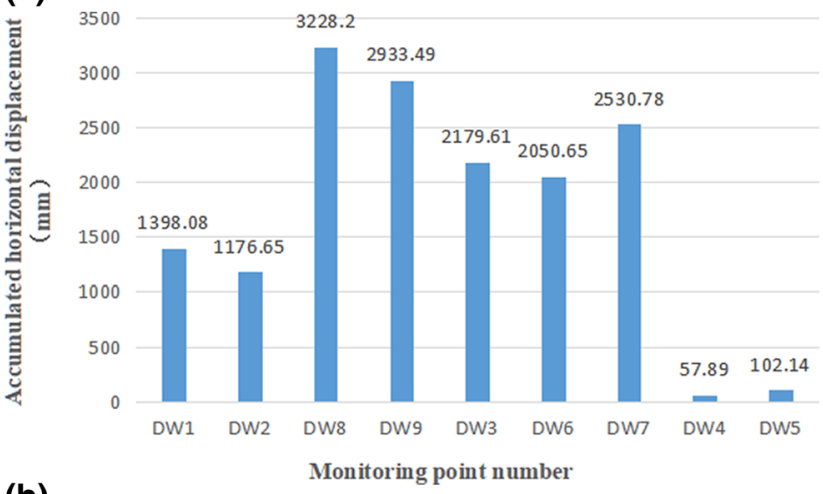

(b)

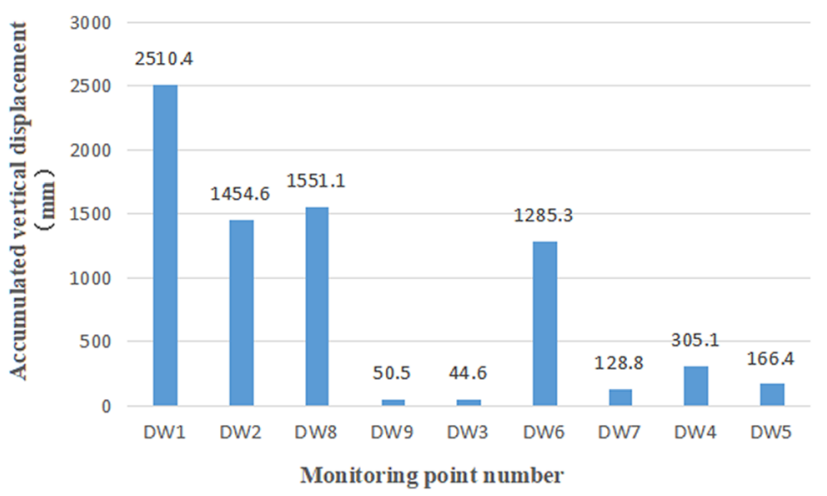

Fig. 4 Cumulative displacement of the monitoring points. a Diagram of values of cumulative horizontal displacement vector. b Cumulative vertical displacement

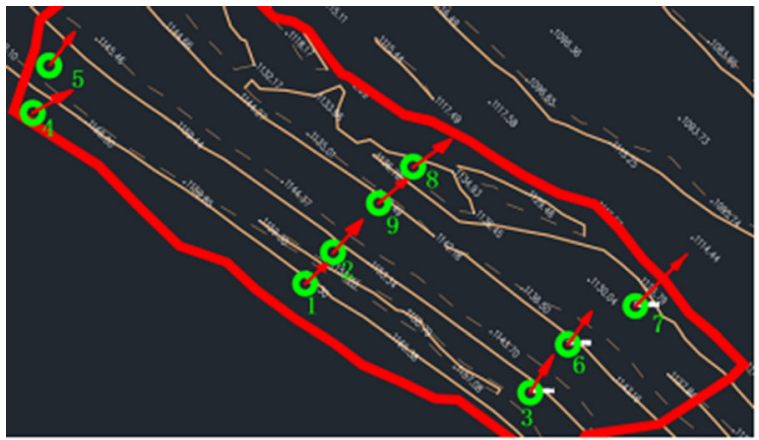

Fig. 5 Track of displacement vector of GPS monitoring points

Monitoring hole ZK1 was far from the back edge of the landslide, and did not slide. Its main function was to expose the distribution of the underground strata. The results for monitoring points ZK2 and ZK3 in section P-1, ZK5 and ZK6 in section P-2, and ZK4 in section P-3 are shown in
Fig. 8 Diagrams of data on displacement depths obtained through the inclinometer. a Curve of depth of displacement-at ZK2. b Curve of depth of displacement - at ZK3. c Curve of depth of displacement-at ZK5. d Curve of depth of displacement-at ZK6. e Curve of depth of displacement—at ZK4
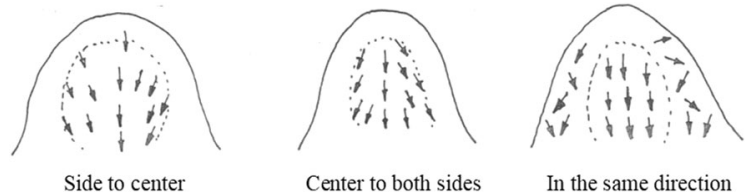

Center to both sides

In the same direction

Fig. 6 Features of plane displacement vector of the observation points

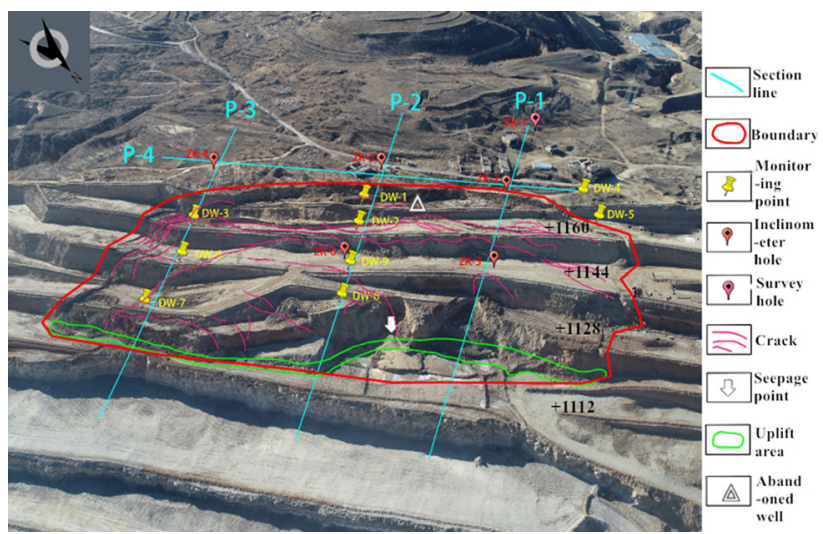

Fig. 7 Diagram of distribution of drilling in ZK1-6

Fig. 8. The diagram of cumulative displacement shows clear displacements at $32 \mathrm{~m}$ at ZK3, $28 \mathrm{~m}$ and $35 \mathrm{~m}$ at ZK5, $27.8 \mathrm{~m}$ at ZK6, and $38 \mathrm{~m}$ and $50 \mathrm{~m}$ at ZK4. The cumulative displacement was relatively small compared with that in the upper part. Therefore, the positions of the sliding surface and the evolving weak layer could be inferred.

Based on an analysis of the monitoring data, the main direction of sliding of the potential sliding body was determined to vary from $31^{\circ}$ to $48^{\circ}$. Combined with a geological engineering survey and a sliding survey, we determined that the sliding surface was located in the weakly evolving layer at the interface of strongly weathered mudstone and sandstone, and was $27-35 \mathrm{~m}$ below the surface. The slope was in a critical sliding state, which represented the shear failure mode. 
718

Z. Hongze et al.

(a) Incremental displacement depth curve in direction A

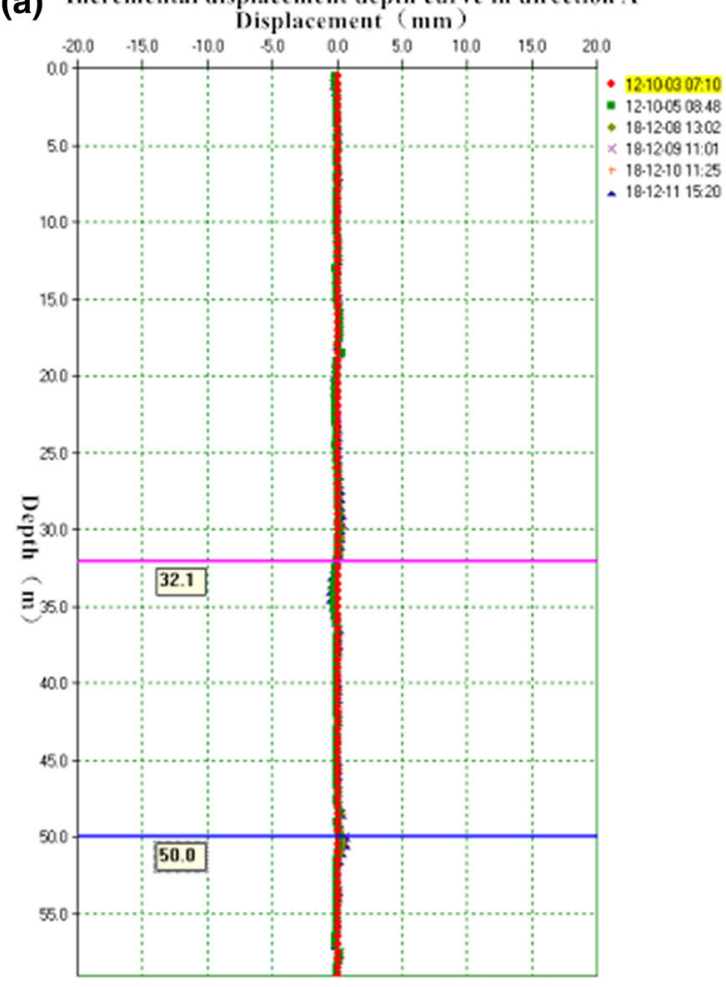

(b)

Incremental displacement depth curve in direction $\mathrm{A}$

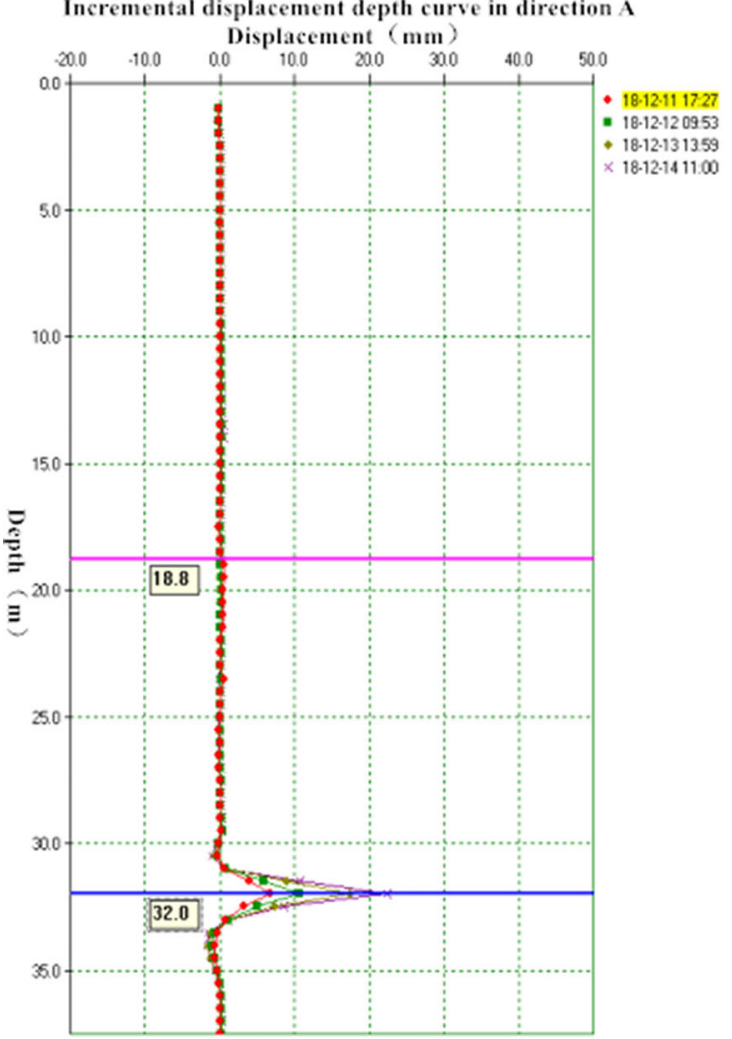

Cumulative displacement depth curve in direction A
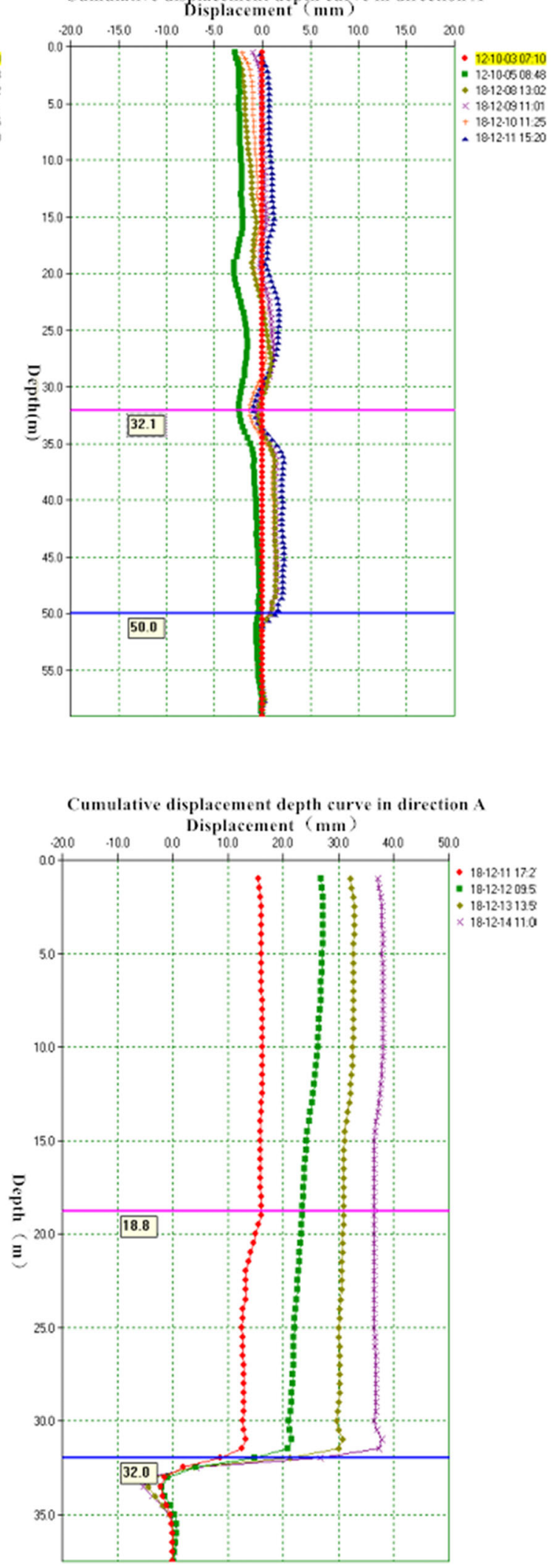

黛 Springer 
(c) Incremental displacement depth curve in direction $\mathrm{A}$

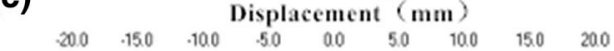

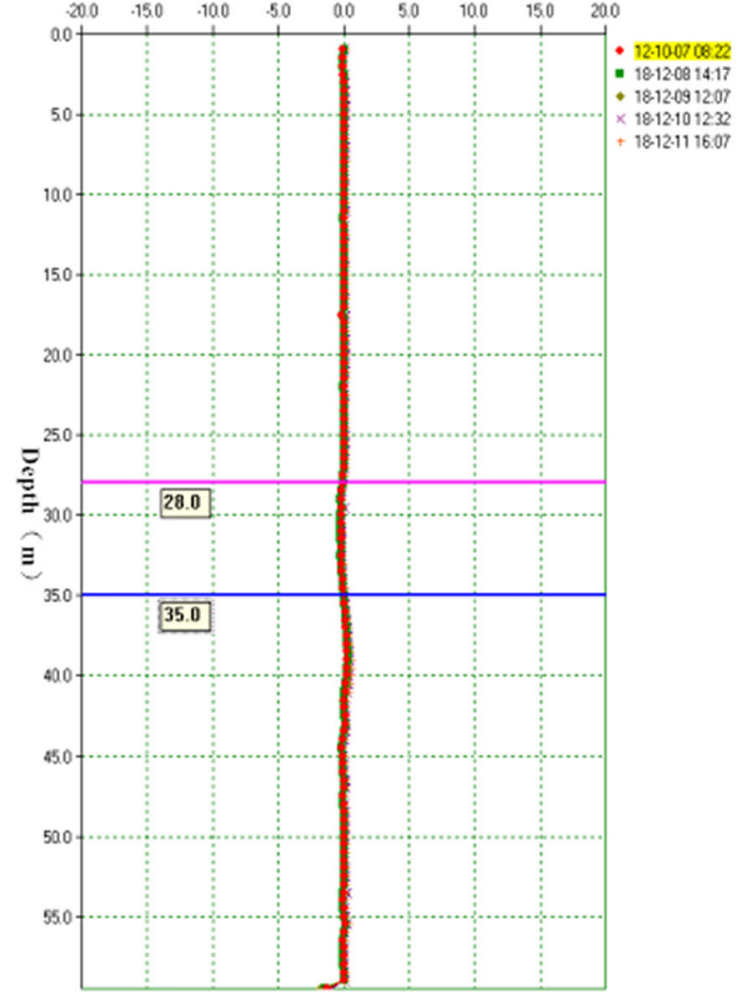

(d)

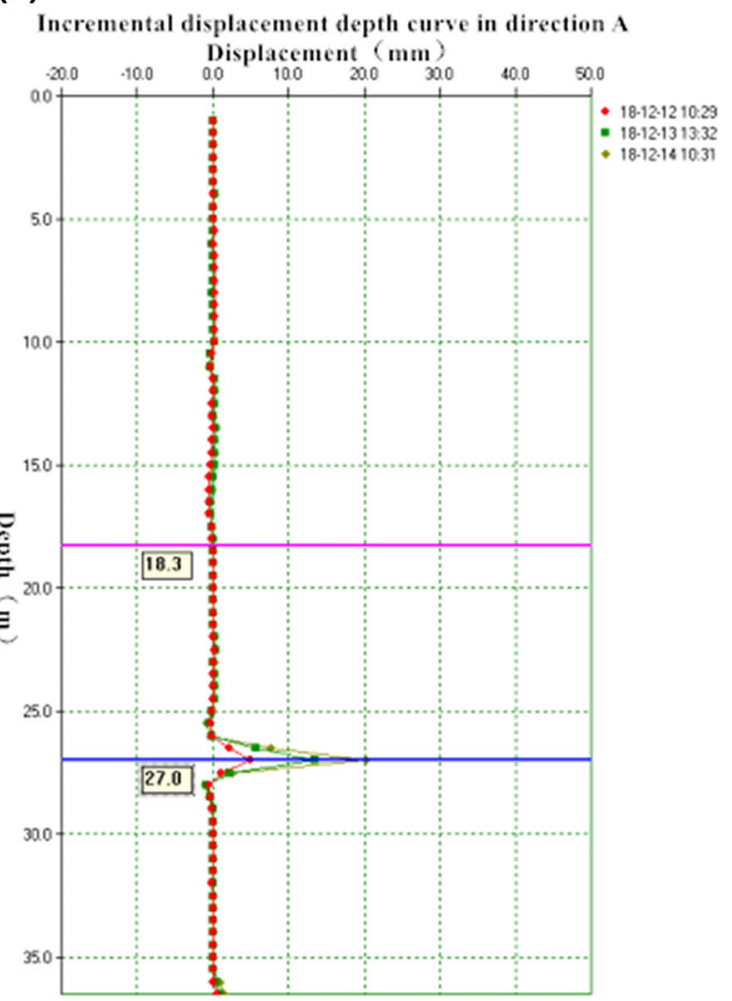

Cumulative displacement depth curve in direction $\mathrm{A}$

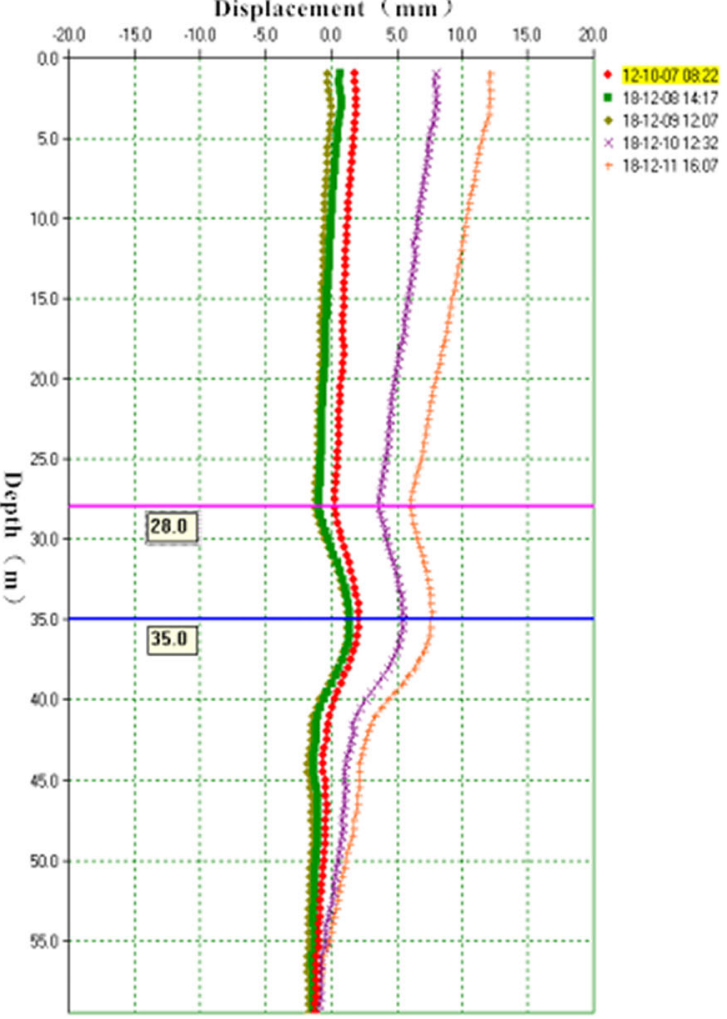

Cumulative displacement depth curve in direction $\mathrm{A}$

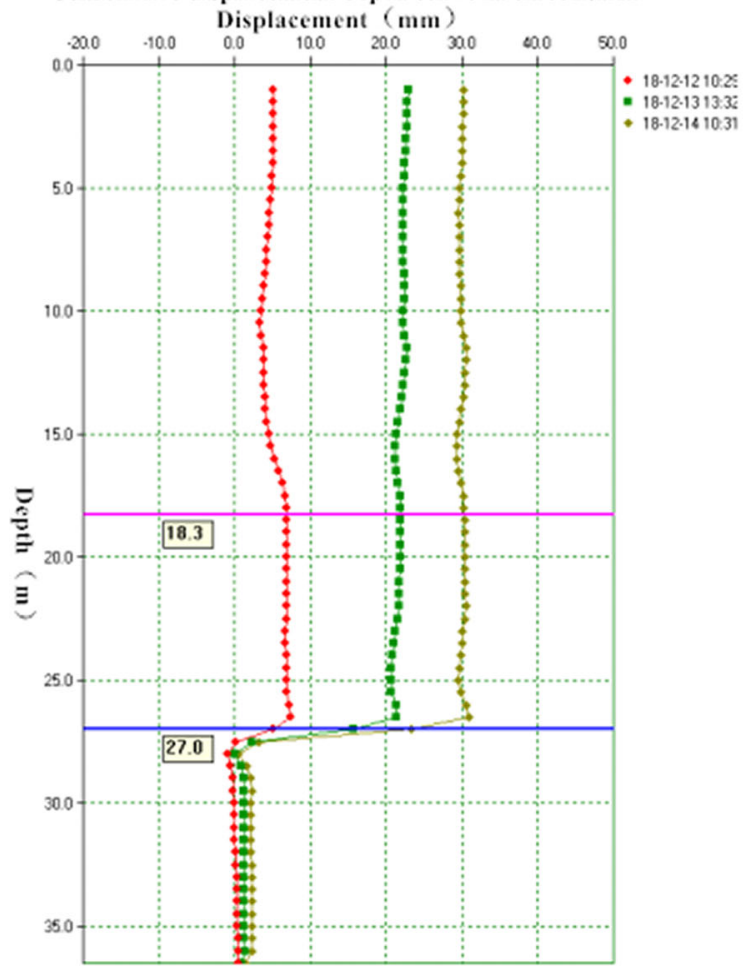

Fig. 8 continued 
(e) Incremental displacement depth curve in direction A

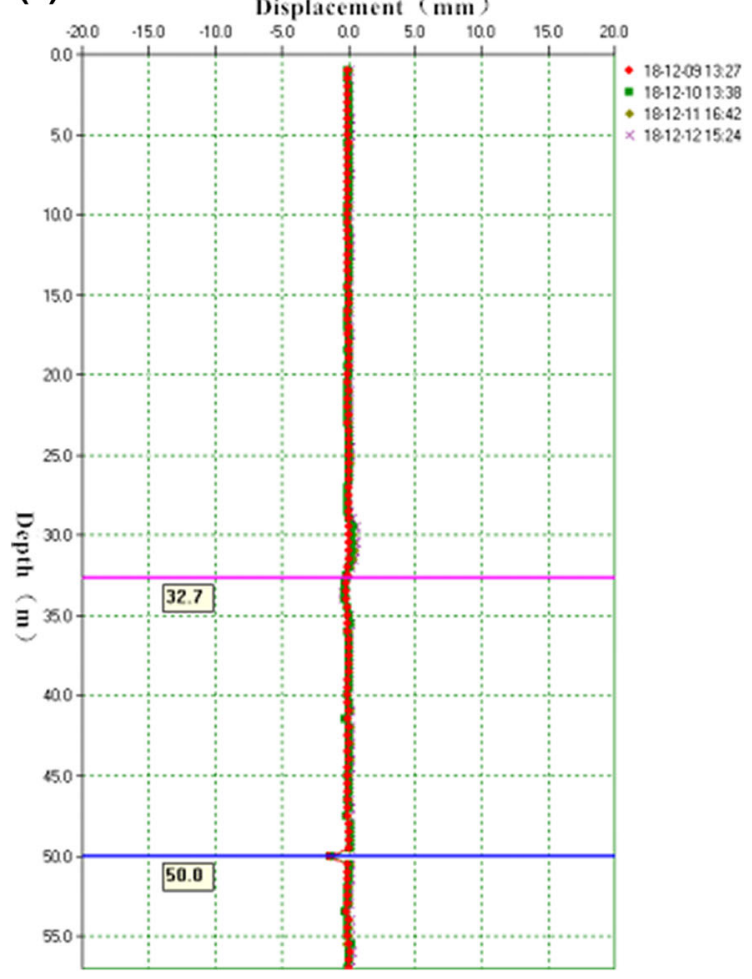

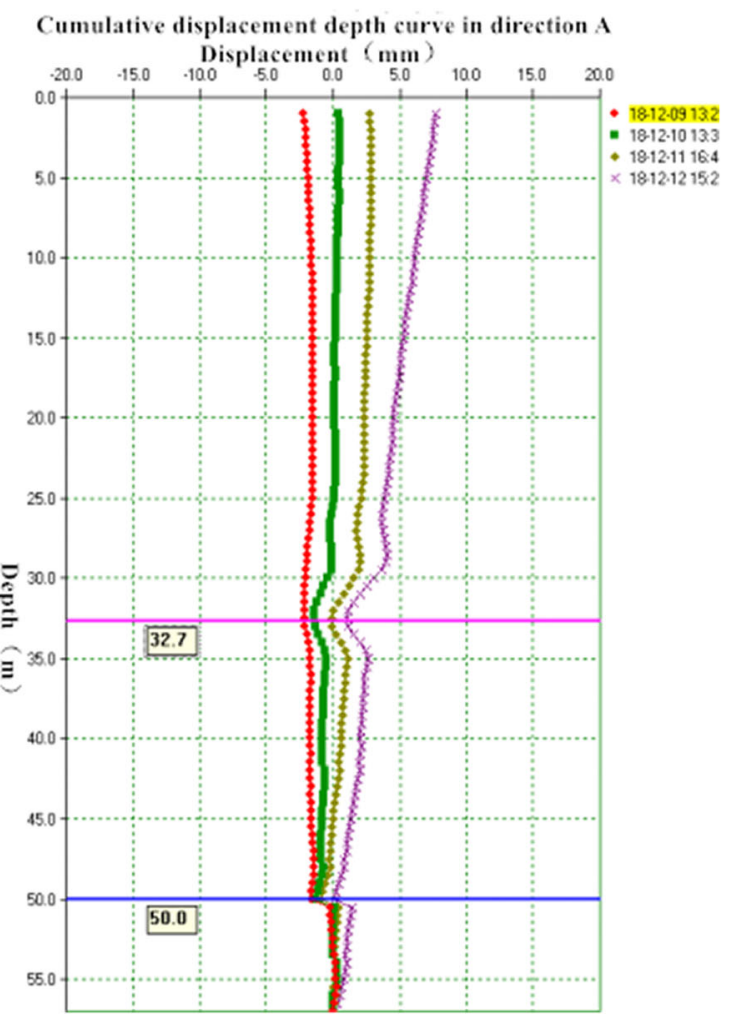

Fig. 8 continued

\section{Numerical simulation}

\subsection{Inversion analysis of mechanical parameters}

As shown in Fig. 9, according to the field survey, the evolving weak layer accumulated at the foot of the slope. It was muddy, and was in a condition similar to that of a minimal alluvial fan. There was no accumulation on the surface, but it spread out on all sides, indicating that the internal friction angle was very small.

As the drilling failed to score the evolving weak layer formed by the water-soaked mudstone, the strength of its evolution was analyzed using inversion analysis. By using historical data on the mechanical parameters of the weak layer in this area, the range of the shear strength index was calculated through a back analysis of the landslide. Based on the field monitoring data, we learned that the slope was in the critical sliding state. The stability of the landslide was thus checked and calculated based on the limit equilibrium analysis principle, and the results are shown in Fig. 10.

The reliability of numerical results depends on the establishment of a calculation model. The physical and mechanical properties of the main rock and Earth mass of

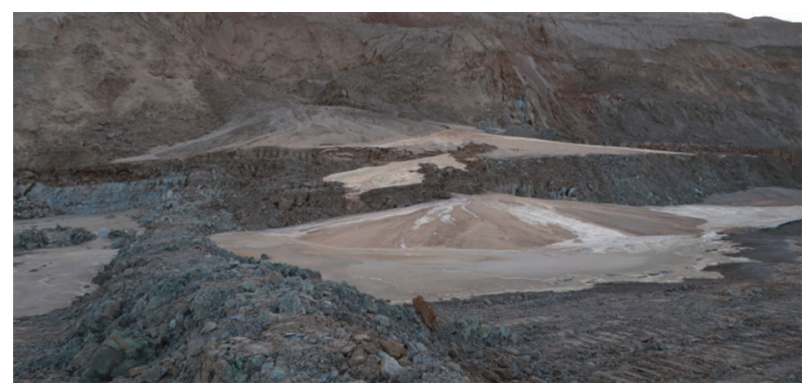

Fig. 9 Weak outcrop at the foot of the slope

the working side of the slope of the Weijiamao open-pit mine were tested in the laboratory. Combined with the results of many past studies, the results of the back analysis method were considered and reasonable values were obtained. According to an analysis of the obtained field monitoring data, the slope was in the critical sliding state. Figure 10 shows that when the coefficient of stability was one, the results of the simulation were consistent with the field monitoring data when the internal friction angle was $6.5^{\circ}$ and cohesion was $14 \mathrm{kPa}$. The physical and mechanical parameters of the rock and the Earth mass from the numerical simulation are shown in Table 2. 


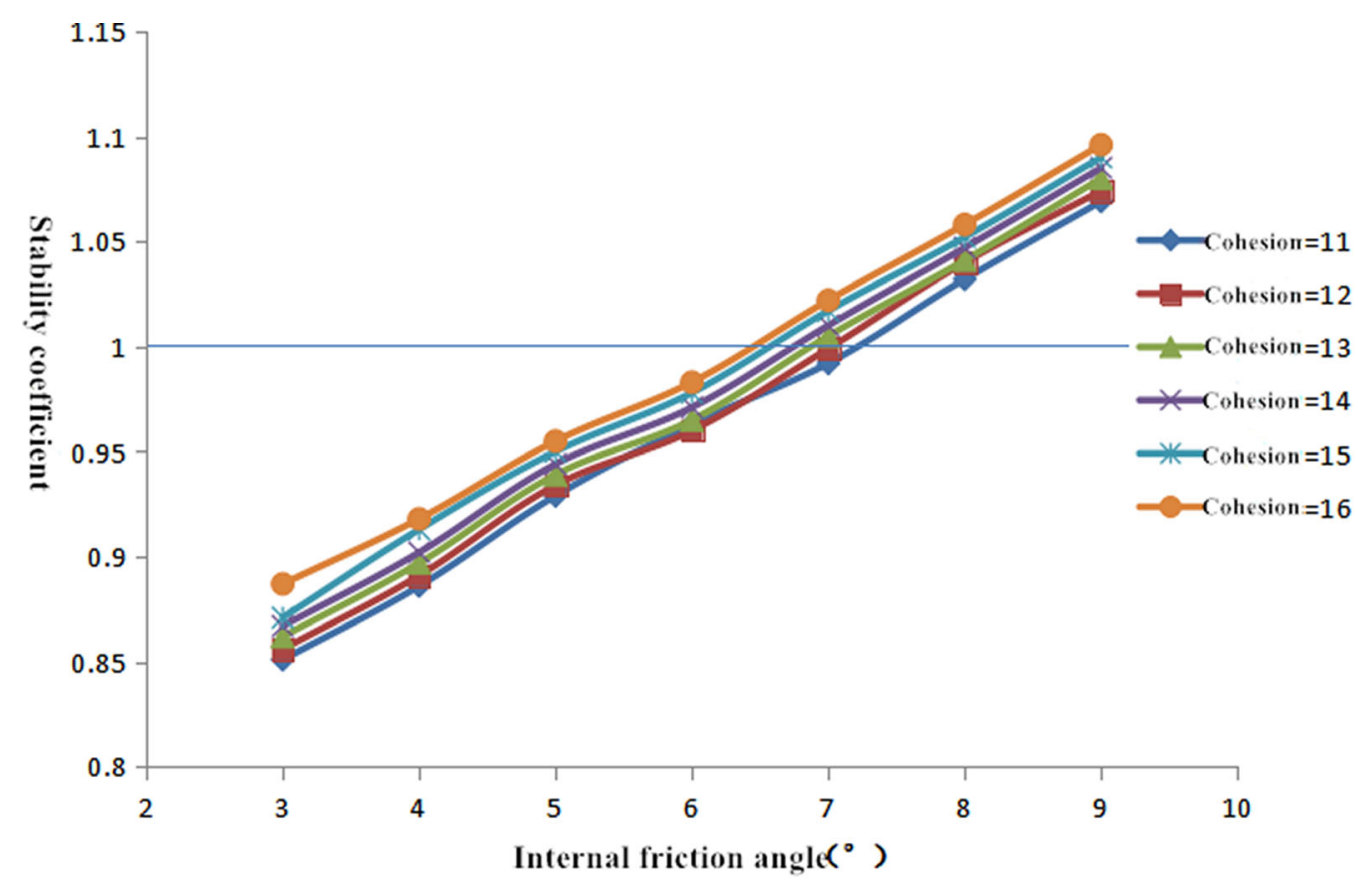

Fig. 10 Relationships among varying cohesion and internal friction angles, and the coefficient of stability of the slope

Table 2 Recommended values of physical and mechanical parameters of rock mass

\begin{tabular}{llcclll}
\hline $\begin{array}{l}\text { Formation } \\
\text { characteristics }\end{array}$ & $\begin{array}{l}\text { Bulk } \\
\text { density } \\
(\mathrm{kN} /\end{array}$ & $\phi\left(^{\circ}\right)$ & $C(\mathrm{kPa})$ & $E(\mathrm{MPa})$ & $\mu$ & Remark \\
& $\left.\mathrm{m}^{3}\right)$ & & & & & \\
\hline Silt & 18.0 & 18.36 & 7.91 & - & - & Natural \\
Silty soil & 18.7 & 22.15 & 20.8 & 9.61 & 0.40 & Natural \\
Silty clay & 20.9 & 23.32 & 46.00 & 2.49 & 0.32 & Saturated \\
Silty clay & 19.3 & 27.4 & 61.80 & - & - & Natural \\
Mudstone & 24.9 & 24.12 & 29.30 & 12.20 & 0.22 & Saturated \\
Weak layer & 21.0 & 6.50 & 14.00 & - & - & Natural \\
Sandstone & 26.0 & 25.00 & 120.00 & 122.00 & 0.34 & Natural \\
\hline
\end{tabular}

\subsection{Verifying the calculated failure mode and location}

The exploration line P-1 of the slope line was chosen for the numerical analysis. The calculation model had a dip length of $406 \mathrm{~m}$ along the slope and a maximum vertical height of $96 \mathrm{~m}$. It is shown in Fig. 11. The front and back of the model were constrained by displacement in the $Y$ direction, its left and right directions were constrained by that in the $X$ direction, and the bottom of the model was constrained by displacement in the $Z$ direction. These constraints formed boundary conditions for displacement to

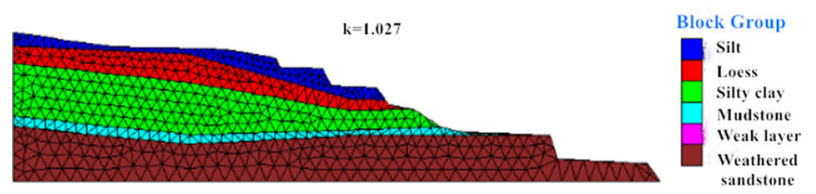

Fig. 11 Calculation model for section P-1

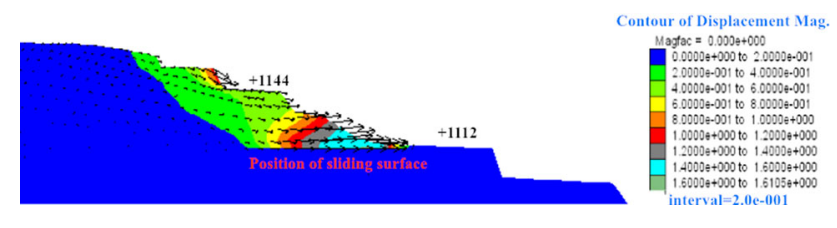

Fig. 12 Cloud diagram of slope displacement vector of section P-1

maintain the force balance of the entire system. The MohrCoulomb model was used for calculation.

The distribution of the slope displacement vector is shown in Fig. 12. It reached its maximum value at the shear zone of the front edge, indicating the tendency of slope traction sliding. Because of the presence of the evolving weak layer in the slope, once the front edge had been peeled off, the bottom bedding of the back edge of the slope slid in an arc shape along the evolving weak layer, causing damage to the overlying silt and the silty sand layer. The red line in Fig. 13 indicates the sliding surface and the blue line the groundwater level. Two GNSS monitoring points were arranged along the back edge of the slope. The horizontal displacement of monitoring point DW4 was calculated at $57.89 \mathrm{~mm}$ and its vertical 


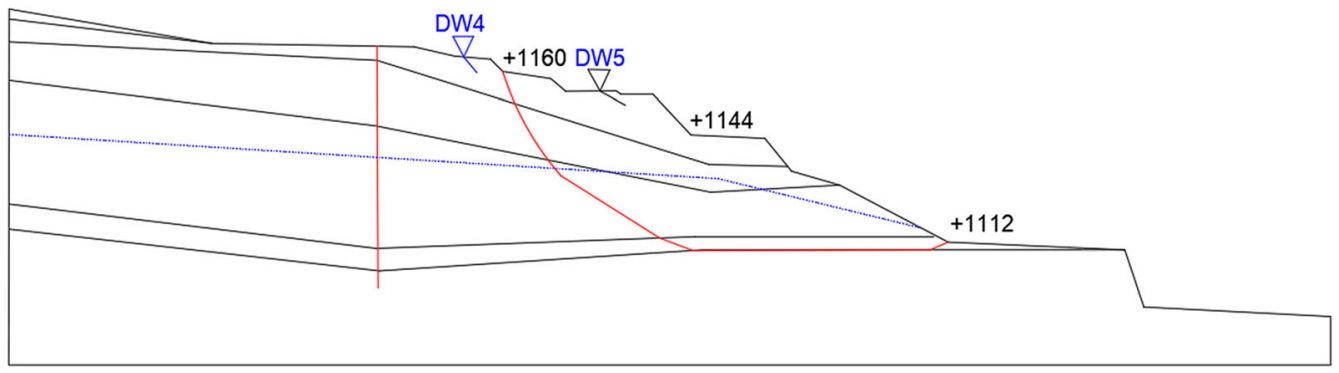

Fig. 13 Displacement vector diagram for slope monitoring

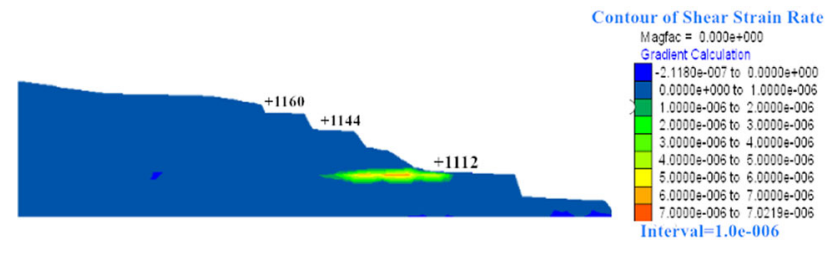

Fig. 14 Cloud chart of shear strain rate of P-1 section slope

displacement was $50.5 \mathrm{~mm}$. The horizontal displacement of monitoring point DW5 was $102.14 \mathrm{~mm}$ and its vertical displacement was $44.6 \mathrm{~mm}$. Combining Figs. 12 and 13, it is clear that the direction of the vector of the monitoring points was consistent with the results of the simulation, where this verified the reliability of its results. Deep displacement monitoring was carried out on the $+1144 \mathrm{~m}$ berm of the section, where the depth of the slide zone was $32 \mathrm{~m}$. It was located at the interface of the mudstone floor and sandstone, and shear deformation at this position was also consistent with the results of the simulation.

A cloud chart of the shear strain rate of the slope is shown in Fig. 14. This rate reached its maximum value at the foot of the slope of the sliding surface, which verified that the foot crept first and caused the sliding and gradual failure of the back edge once the slope had begun stripping. According to the distribution of displacement vector of slope, it can be determined that the failure mechanism of slope body is mainly excavation unloading shear failure. In the macroscopic mode, it is a traction landslide of creepage tension crack type, and the failure mode of floor bedding back edge circular arc shear is located flat push.

The slope was unstable on the whole in the zone of weak strength or the area of stress concentration, and the soil element in this area generated different degrees of unrecoverable plastic deformation. If the weak zones or areas of stress concentration with plastic deformation were connected with one another, this indicates that the slope was unstable on the shear failure surfaces. The occurrence and development of plastic strain indicate the occurrence and degree of development of soil yield or failure. The size of plastic strain can be used to describe the development of soil yield or failure. Therefore, the connection among the

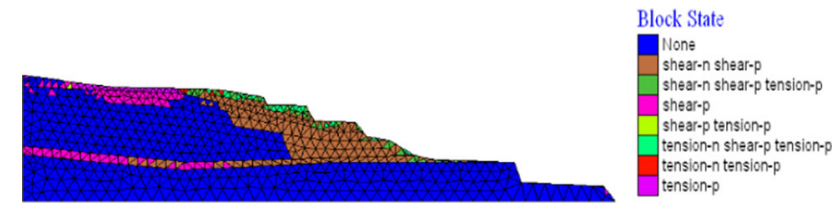

Fig. 15 Schematic diagram of plastic zone of slope in section P-1

plastic zones was used to evaluate the overall instability and failure of the slope.

As shown in Fig. 15, the distribution of the area of shear plastic yield indicated that the plastic area penetrated the entire sliding body, and the slope was unstable, ranging from $\mathrm{a}+1112 \mathrm{~m}$ level to $\mathrm{a}+1160 \mathrm{~m}$ level. The trend of its direction was upward, and a certain area of the silty sand layer at the back edge of the slope also had a tensile plastic area, which indicates that the rock and Earth masses at the foot of the slope underwent shear yield after excavation. This caused the slope to be gradually damaged, and it moved backward to become unstable. At the surface level of $+1160 \mathrm{~m}$, tensile failure appeared accompanied by associated cracks, which was also consistent with the state whereby a large number of tensile cracks appeared at the back edge of the slope.

From the above analysis, it is clear that the position of the sliding surface in the body of the slope where exploration line P-1 was located was in the weakly evolving layer at the interface of the strongly weathered mudstone and sandstone. The depth was $32 \mathrm{~m}$ below $+1144 \mathrm{~m}$, and the failure mechanism was shear failure. The results of the numerical simulation were consistent with the field monitoring data.

\subsection{Section analysis of potential failure mode in landslide area}

Exploration line P-1 was located along the edge of the slope where the landslide had occurred. An analysis of this line can thus help clarify the mechanism of the landslide and position of the sliding surface to prevent a secondary landslide. Exploration line P-2 was located along the 
central axis of the slope where the landslide had occurred. The analysis can show the correctness of the analysis of exploration line P-1. Moreover, the feasibility of the parameter inversion method and accuracy of the location determination method can be verified more accurately through a simulation of exploration lines P-1 and P-2.

The working slope of exploration line P-2 was selected as profile line for the numerical analysis. The calculation model is shown in Fig. 16.

The distribution of the displacement vector of the slope is shown in Fig. 17. Once the location of the entire slope had been identified and it slid, floor heave was formed over a small range at the foot of the slope, but there was no effective presser foot for its overall stability. The maximum deformation of the slope still occurred at the foot of the front edge of the evolving weak layer, which reflected the next trend of sliding of the slope. Combined with the shear strain of the slope shown in Fig. 18, we concluded that the slope would continue to creep along the weak layer.

The distribution of the plastic zone of the slope in section P-2 is shown in Fig. 19. This zone was still in the running-through state, and its safety factor was 1.064; thus, the shallow water in the slope is in frost heaving state in winter, and the strength of rock and soil is higher than that in normal state, so the slope is temporarily stable.

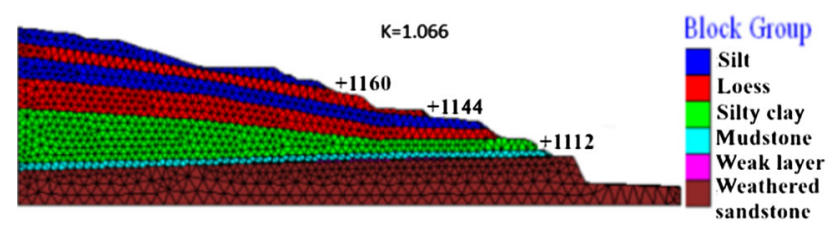

Fig. 16 Calculation model for section P-2

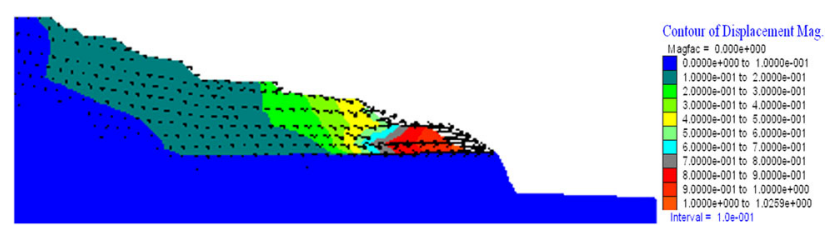

Fig. 17 Vector cloud diagram of slope displacement in section P-2

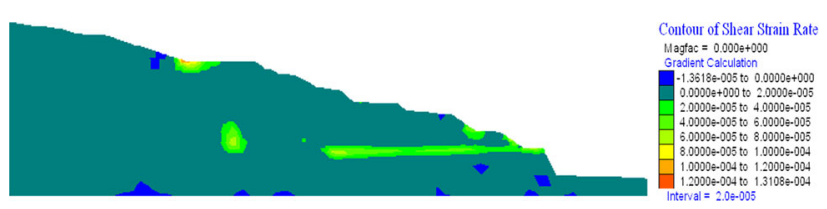

Fig. 18 Cloud chart of shear strain rate of slope in section P-2

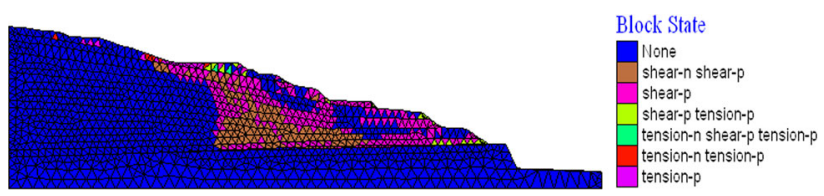

Fig. 19 Plastic zone of slope in section P-2

In conclusion, based on the analysis of the working slope in the mining area, its failure mechanism and failure mode were analyzed using intuitive features of its displacement and deformation, the state of shear strain, and expansion of the plastic zone. The results show that the bottom bedding back edge of the slope slid in an arc shape along the evolving weak layer, causing damage to the overlying silt and the silty sand layer. The slope exhibited an excavation unloading-shear failure mechanism, and a creep-tensile traction landslide in the macroscopic mode, which was a horizontal sliding failure mode, in the forms of the shears of the floor bedding-back edge arc. Plastic zones in the body of the slope were connected, and it was unstable.

\section{Conclusions}

(1) Data from nine ground GNSS monitoring points and six deep displacement monitoring points were obtained by using an inclinometer. The position of the landslide of the open-pit mine was thus located in the weak evolution layer at the interface of strongly weathered mudstone and sandstone. The weak evolution layer was $32 \mathrm{~m}$ below $+1144 \mathrm{~m}$, and the angle of the landslide ranged from $31^{\circ}$ to $48^{\circ}$. Sections of exploration lines P-1 and P-2 were analyzed, and the accuracy of the results was verified by a numerical simulation.

(2) Through parameter inversion using the FLAC3D simulation software, we concluded that the internal friction angle of the evolving weak layer in the slope of the Weijiamao open-pit mine was $6.5^{\circ}$ and cohesion $C$ was $14 \mathrm{kPa}$. The results of the architectural model were consistent with the field monitoring data, which verified the feasibility of the parameter inversion method.

(3) The bottom bedding of the back edge of the slope in the open-pit mine slid in an arc shape along the evolving weak layer, which caused damage to the overlying silt and the silty sand layer. The slope exhibited an excavation unloading-shear failure mechanism, a creep-tensile traction landslide in the macroscopic mode, and a creep-tensile traction landslide in the macroscopic mode, which was a 
horizontal sliding failure mode, in the forms of the shears of the floor bedding-back edge arc. Plastic zones in the body of the slope were connected, and it was unstable.

(4) For the slope as controlled by the evolving weak layer, features of its deformation and failure mainly depended on the rheological features of the weak layer, while the shear strength of the weak layer changed over time. The long-term weakness of the evolving weak layer is an important factor influencing slope failure.

Acknowledgements This work was supported by the State Key Laboratory for Geomechanics and Deep Underground Engineering, China University of Mining and Technology, Beijing (No. SKLGDUEK1923) and Special fund for basic scientific research of central universities (Grant no: 2013QZ04).

Open Access This article is licensed under a Creative Commons Attribution 4.0 International License, which permits use, sharing, adaptation, distribution and reproduction in any medium or format, as long as you give appropriate credit to the original author(s) and the source, provide a link to the Creative Commons licence, and indicate if changes were made. The images or other third party material in this article are included in the article's Creative Commons licence, unless indicated otherwise in a credit line to the material. If material is not included in the article's Creative Commons licence and your intended use is not permitted by statutory regulation or exceeds the permitted use, you will need to obtain permission directly from the copyright holder. To view a copy of this licence, visit http://creativecommons. org/licenses/by/4.0/.

\section{References}

Bai J (2018) Orthogonal-design-based back analysis on strength parameters of slope deformed body. Northwest Hydropower 37:88-91, 95

Cao LZ, Zhao LC, Wang D, Pu FS, Li W, Li ZB, Song ZL (2015) Three-dimensional numerical analysis on landslide control of composite slope with multiple weak layers. J Saf Sci Technol 11(6):102-107

Chang X, Liu S (2018) Research on displacement back analysis based on mechanical parameters of open-pit slope. China Coal 44(12):36-40

Feng XT, Katsuyama K, Wang YJ, Lin YM (1997) A new directionintelligent rock mechanics and rock engineering. Int $\mathrm{J}$ Rock Mech Min Sci 34(1):135-141

Holland JH (1992) Adaptation in natural and artificial systems: An introductory analysis with applications to biology. control, and artificial intelligence. U Michigan Press, Ann Arbor

$\mathrm{Hu}$ B, Feng X, Wang G, Chen BR, Zhou H (2005) Intelligent inversion of creep parameters of mudstone mass on the left bank high slope of Longtan hydropower station. Chin J Rock Mech Eng 24(17):3064-3070

Kesavan M, Bekir G (2020) Dynamic simulation of an opencast coal mine: a case study. Int J Coal Sci Technol 7(1):164-181

Li S, Lv S, Zhang C (1998) Creep mechanism and monitoring data analysis of an engineering slope. Chin J Rock Mech Eng 17(2):34-35

Liu G, Hu D, Xu G (2004) Application of inclinometer in monitoring construction of soft embankment. Soil Eng Found 18(3):57-60

Liu Z, Ning H, Zhang H (2006) The method and progress of back analysis of displacement in geotechnical engineering. Subgrade Eng 05:7-10

Lu N, Han M (2018) Application of sliding slope back analysis in the Inner Mongolia open-pit mine. Opencast Min Technol 33(04):51-53, 57

Lu K, Zhu D (2014) Theoretical and experimental study of effect of slope topography on its stability. Chin J Rock Mech Eng 33(1):35-42

Shang T, Han L, Shu JS, Chen SZ (2019). Slope structure and stress development rule under mining mode of land saving and ecological detraction. J China Coal Soc 44(12):3644-3654

Tian M, Zhou J (2005) New algorithm for parameter inversion in geotechnical engineering. Chin J Rock Mech Eng 24(09):1492-1496

Zhang Q, Gao Y, Li S (2005) Study on 3D-displacement inversion method for mechanical parameters of mine overlying rock. Metal Mine 09:26-31

Zhao HZ, Tian Y, Guo QY, Li MJ, Wu JW (2020). The slope creep law for a soft rock in an open-pit mine in the Gobi region of Xinjiang, China. Int J Coal Sci Technol. https://doi.org/10.1007/ s40789-020-00305-4 